\title{
Article \\ Early Weak Fault Diagnosis of Rolling Bearings Based on Fiber Bragg Grating Sensing Monitoring
}

\author{
Xinxin Chen ${ }^{1,2}$, Yali Jiang ${ }^{1,2}$, Boning Zhou ${ }^{1,2}$, Hui Zhan ${ }^{1,2}$, Hongwei Li ${ }^{1,2}$, Guohui Lyu ${ }^{1,2, *, \dagger}$ \\ and Shuli Sun $1, *,+\mathbb{D}$ \\ 1 College of Electronic Engineering, Heilongiang University, Harbin 150080, China; \\ chen.xinxin@hrbu.edu.cn (X.C.); 2171238@s.hlju.edu.cn (Y.J.); 2201613@s.hlju.edu.cn (B.Z.); \\ 2000092@hlju.edu.cn (H.Z.); li_hw@hlju.edu.cn (H.L.) \\ 2 National and Local Joint Engineering Research Center of Optical Fiber Sensing Technology, \\ Heilongjiang University, Harbin 150080, China \\ * Correspondence: lvguohui@hlju.edu.cn (G.L.); sunsl@hlju.edu.cn (S.S.) \\ + Shuli Sun is the first corresponding author. Guohui Lyu is the second corresponding author.
}

Citation: Chen, X.; Jiang, Y.; Zhou, B.; Zhan, H.; Li, H.; Lyu, G.; Sun, S. Early Weak Fault Diagnosis of Rolling Bearings Based on Fiber Bragg Grating Sensing Monitoring. Symmetry 2021, 13, 1473. https://doi.org/10.3390/ sym13081473

Academic Editor: Jan Awrejcewicz

Received: 21 July 2021

Accepted: 9 August 2021

Published: 11 August 2021

Publisher's Note: MDPI stays neutral with regard to jurisdictional claims in published maps and institutional affiliations.

Copyright: () 2021 by the authors. Licensee MDPI, Basel, Switzerland. This article is an open access article distributed under the terms and conditions of the Creative Commons Attribution (CC BY) license (https:// creativecommons.org/licenses/by/ $4.0 /)$.

\begin{abstract}
Aiming at the problems of weak dynamic response and difficulty in diagnosis of early damage of rolling bearings, a diagnosis method for early damage of rolling bearings is proposed. Taking radial rolling bearings as the main research object, the load symmetric structure of deep groove ball bearings is analyzed. Based on the mechanical second-order system theory, the sensor monitoring structure is constructed. The generalized resonance principle is used to identify weak signals, and the fiber Bragg grating is used for signal sensing. The signal is obtained through the fiber Bragg grating high-speed demodulator. When a continuous periodic generalized resonance wave appears in the amplitude-frequency analysis of the signal, and there is a high-frequency resonance frequency, it can be proved that the bearing is faulty. The diagnosis method can effectively avoid the interference of low-frequency signals, the frequency spectrum is pure and there is no electromagnetic interference. It fully shows that the fiber Bragg grating sensor is suitable for the monitoring and diagnosis of the early weak fault of the bearing.
\end{abstract}

Keywords: bearing fault diagnosis; symmetry analysis; generalized resonance wave; fiber Bragg grating; natural frequency

\section{Introduction}

Rolling bearings are one of the important basic parts of mechanical equipment [1]. The working environment of bearings is often very harsh, and the load borne in the process of operation is also large, which is prone to damage and leads to functional fault; this brings serious threats to the operation of the whole piece of mechanical equipment and the safety of staff $[2,3]$.

At first, the damage status of bearings can be judged by real-time monitoring of bearing temperature. Although this method is simple, early damage of bearings cannot be detected in time $[4,5]$. Because the damage vibration information is relatively weak, it is difficult to extract the signal, and it is also difficult to realize early bearing damage detection [6]. Bearing damage signal can be amplified by the resonance principle, but its frequency turns to low-frequency with the aggravation of damage impact, so it is not suitable for early bearing damage detection [7]. Bearing damage of generalized resonance monitoring technology is based on the generalized resonance phenomenon. When the instantaneous impact of bearing damage acts on the sensor, the short-term impact pulse contains a series of continuous frequency components from zero to infinity. The frequency component whose vibration frequency is equal to the natural frequency of the sensor will have an effect on the sensor. Free damping vibration is carried out at this frequency and the free damping vibration signal is analyzed to diagnose whether bearing damage has 
occurred. SKF, a Swedish company, developed a portable pulse vibrometer, which can judge the degree of bearing damage by monitoring the amplitude of the shock wave energy of bearing damage. However, a local detection method cannot determine which part of the bearing is damaged [8]. In 2012, Deyao Tang proposed a piezoelectric generalized resonance bearing damage monitoring sensor based on the generalized resonance principle. Using piezoelectric ceramics as sensitive devices, the measured temperature signals and vibration signals are processed and demodulated by an electronic modulator, and the generalized resonance bearing damage monitoring can be realized. The sensor has a good application prospect for the monitoring and diagnosis of early damage of bearings. However, the drawback is that the piezoelectric ceramic sensor based on piezoelectric effect is not resistant to electromagnetic interference and the working environment of bearings is often very harsh, which has a great influence on the results of diagnosis $[9,10]$.

In this paper, the small and sensitive fiber Bragg grating (FBG) is used to accurately extract early damage vibration signals from bearing damage signals. The generalized resonance signal of the sensor is demodulated by a high-speed FBG demodulator, and the characteristics of the vibration signal in time domain and frequency domain are analyzed to realize the identification and diagnosis of the weak fault signal of the bearing in the early stage. The detection method is fast and accurate and is suitable for harsh working environments.

\section{Bearing Structure and Fault Characteristic Frequency}

\subsection{The Basic Structure of Bearing and the Analysis of Structural Symmetry}

The bearing is composed of four parts: inner ring, outer ring, rolling element and cage. The inner ring is fixed to rotate along the shaft. The outer ring is fixed to the housing, which mainly supports and protects the rolling. The rolling element rolls in the cavity formed in the inner ring and the outer ring, maintaining relative movement between the inner ring and the outer ring. The size of the bearing carrying capacity is determined by the number, shape and size of the rolling. The cage can make the rolling element evenly distributed in the roller, always maintains equal spacing, and assigns equal load to each rolling element [11-13]. Figure 1 shows the basic structure of the bearing.

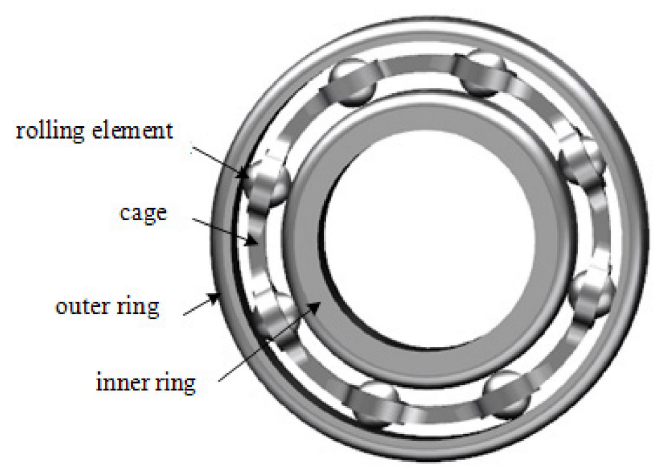

Figure 1. Basic structure of bearing.

The main considerations for bearing selection are load and load direction. According to the load direction, it can be divided into: radial bearing, angular contact bearing and thrust bearing. The radial bearing is a radial bearing with a contact angle of $0^{\circ}$; the contact angle of angular contact bearings is between $0^{\circ}$ and $45^{\circ}$; thrust bearings are mainly used to bear axial loads, and their contact angles are between $45^{\circ}$ and $90^{\circ}$.

Deep groove ball bearings are radial bearings. The rolling elements of uniform mass are equally spaced between the inner ring and the outer ring. The outer ring of the deep groove ball bearing is fixed under the action of radial load [14-16]. The inner ring moves under the action of radial load, producing radial displacement $\delta_{\mathrm{r}} / \mathrm{mm}$. The center position of the rolling element bearing the maximum load is on the same line of action as the 
radial load. Taking the maximum bearing rolling element as the starting point, the radial displacement of the rolling element at any angular position is $\delta_{\psi \mathrm{i}}$. External radial load is $\mathrm{F}_{\mathrm{r}} / \mathrm{N} . \psi_{\mathrm{i}}$ is the angle between the rolling element and $\mathrm{F}_{\mathrm{r}}$. The bearing load distribution diagram is shown in Figure 2. According to the theory of elastic mechanics, the relationship between the radial load borne by the rolling element at any angular position $\psi_{\mathrm{i}}$ and the load borne by the maximum bearing rolling element is:

$$
\mathrm{Q}_{\mathrm{i}}=\mathrm{Q}_{\max }\left[1-\frac{1}{2 \varepsilon}\left(1-\cos \psi_{\mathrm{i}}\right)\right]^{\frac{3}{2}}
$$

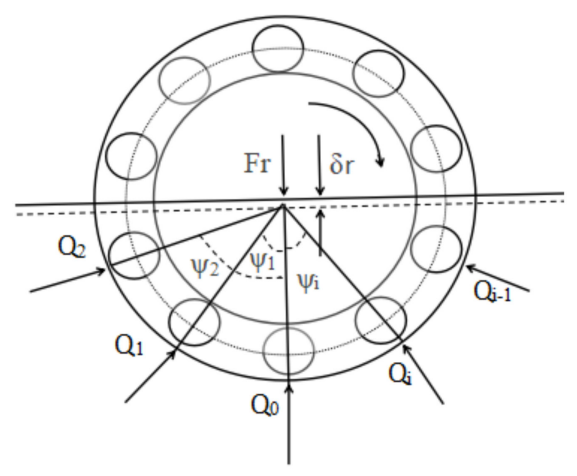

Figure 2. Bearing load distribution diagram.

In Equation (1), $\mathrm{Q}_{\max } / \mathrm{N}$ is the maximum rolling element load. $\varepsilon$ is the load distribution parameter of the bearing.

Because the rolling elements are evenly distributed, $\psi_{1}=\psi_{\mathrm{i}}$. According to Equation (1), we can obtain:

$$
\mathrm{Q}_{1}=\mathrm{Q}_{\mathrm{i}}
$$

From Equation (2), it can be seen that the load at $Q_{1}$ of the deep groove ball bearing is the same as the load at $Q_{i}$. The rolling element 1 and the rolling element $i$ are symmetrical about the central axis. It shows that deep groove ball bearings have a symmetrical force structure when they are under load.

\subsection{Bearing Fault Form and Fault Characteristic Frequency}

When the rolling bearing is working normally, it will be affected by internal factors and external factors. When working at a certain speed and load, it will produce an exciting force for the entire system, thereby promoting the system to vibrate. Therefore, the rolling bearing vibration that is usually working includes natural vibration mode and fault vibration mode. The natural vibration mode is related to the vibration transmission path, processing link, material and other factors, and it is hardly affected by the working state. The fault vibration mode can characterize the working state of the bearing, and by analyzing the characteristics of this type of vibration, it can be judged whether the bearing is malfunctioning. Common fault vibration modes include wear, fatigue, indentation, corrosion, electrical corrosion, cracking, gluing, cage damage, etc. [17].

When a bearing is damaged, a series of short-term impulse excitation forces will be generated, and a frequency different from the normal operation of the bearing will appear in the vibration signal. This frequency is an important basis for bearing damage monitoring technology and is called the fault characteristic frequency [18].

Suppose the number of rolling elements is $Z$, the contact angle of the bearing is $\gamma$, and the operating frequency of the bearing is $f_{s}$. The diameter of the rolling element is $d$. The distance between the centers of the two rolling elements on the same straight line is D, as shown in Figure 3. After a component of the bearing is damaged, the rolling elements make contact with the damage point, causing the bearing to generate periodic short-term pulse excitation force. The calculation formula of the fault characteristic frequency of each part of the bearing is as follows $[19,20]$. 


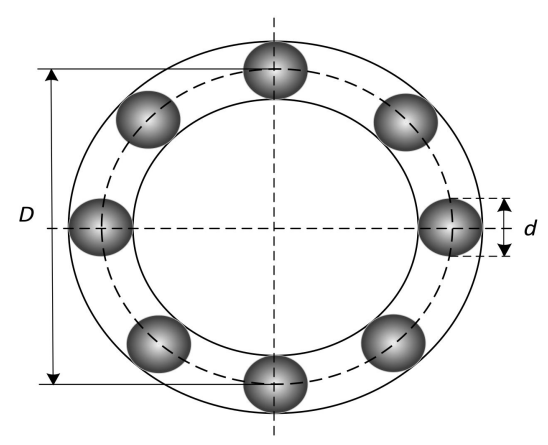

Figure 3. Structure drawing of bearing rolling element.

Inner ring/outer ring fault characteristic frequency:

$$
\mathrm{BPI} / \mathrm{BPO}=\frac{1}{2} \mathrm{Z}\left(1 \pm \frac{\mathrm{d}}{\mathrm{D}} \cos \gamma\right) \mathrm{f}_{\mathrm{s}}
$$

Rolling element fault characteristic frequency:

$$
\mathrm{BS}=\frac{\mathrm{D}}{\mathrm{d}}\left(1-\left(\frac{\mathrm{d}}{\mathrm{D}}\right)^{2} \cos ^{2} \gamma\right) \mathrm{f}_{\mathrm{S}}
$$

Cage fault characteristic frequency:

$$
\mathrm{FT}=\frac{1}{2}\left(1-\frac{\mathrm{d}}{\mathrm{D}} \cos \gamma\right) \mathrm{f}_{\mathrm{s}}
$$

\section{Generalized Resonance Sensor Measurement Principle}

\subsection{Detection Principle of Generalized Resonance Bearings}

Generalized resonance describes the response of the object to the instantaneous impact [21]. At the moment when the instantaneous impact acts on the object, the energy of the impact force is transferred. That is to say, when the object is subjected to the vibration of the impact, it stores the huge energy brought by the impact. When the impact force disappears, the object releases the energy with the free attenuation vibration of its own natural frequency. This process of energy storage and release is called generalized resonance. When the bearing is damaged in the early stage, it will produce vibration signals different from those in normal operation. However, these signs of damage are hard to pick up. Therefore, it is necessary to use the generalized resonance principle to extract and amplify the damage high-frequency signals to realize the online monitoring of bearing machinery and equipment [22]. Figure 4 shows the generalized resonance bearing damage detection process.

\subsection{Principle of Resonance Sensor Bearing Damage Sensing}

The instantaneous pulse generated by bearing damage acts on the sensor, and the sensor absorbs energy to produce a generalized resonance response. FBG is used to monitor the vibration signal and convert the vibration signal into the axial strain of the FBG. That is, by monitoring the dynamic change of the FBG wavelength, bearing damage monitoring and diagnosis can be performed. At the same time, the coupling electromagnetic interference in the vibration signal is avoided.

The vibration sensor based on the sensing principle of FBG can be regarded as a single mass point string vibration model. Figure 5 shows the spring-mass model of equivalent stiffness transformation. This model is mainly a second-order single-degree-of-freedom system composed of an inertial mass $\mathrm{m}$, an elastic coefficient $\mathrm{k}$ and a damper c [23-25]. 


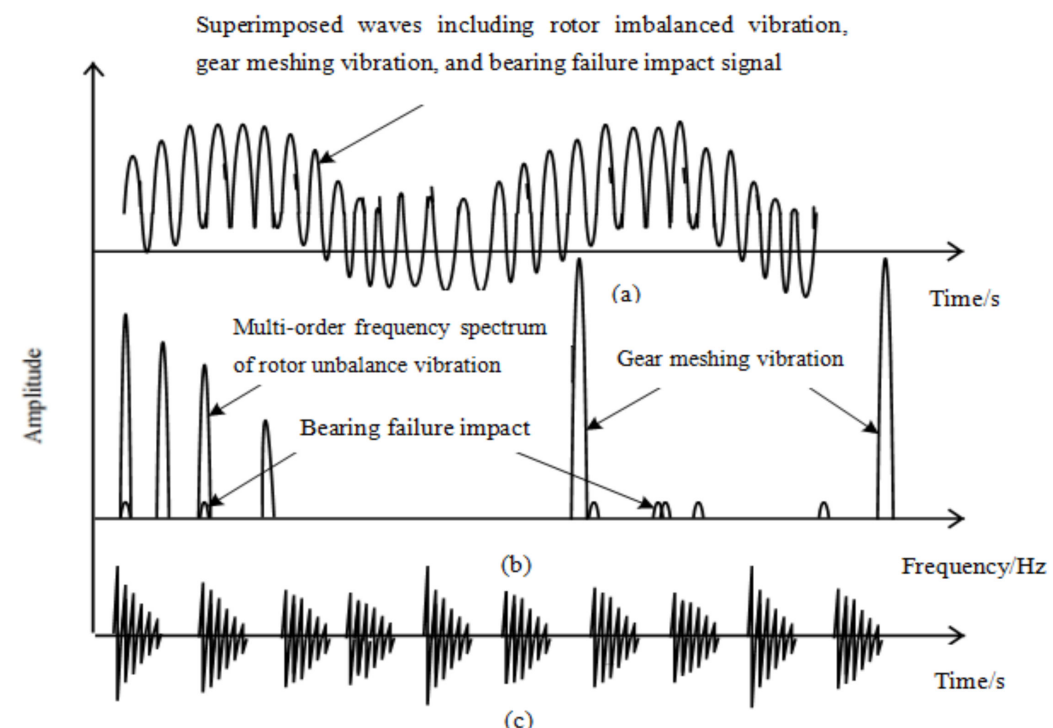

Figure 4. Generalized resonance bearing damage detection technology schematic diagram. (a) Bearing damage vibration signal; (b) Frequency domain characteristics; (c) Generalized resonance wave.

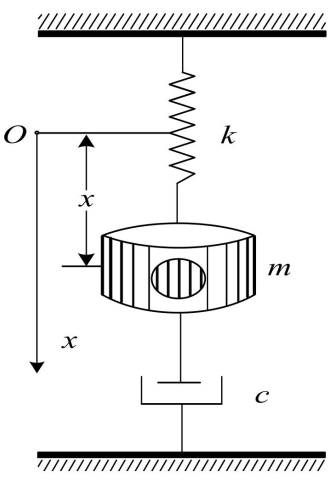

Figure 5. The single mass point string vibration model.

When the excitation force in the vertical direction of a period is applied to the sensor, the amplitude of the excitation force is set as $\mathrm{H}$ and the circular frequency is $\omega$, and the expression of the excitation force is as follows:

$$
\mathrm{S}=\mathrm{H} \sin \omega \mathrm{t}
$$

In Figure 5, the origin of coordinate $\mathrm{O}$ is set at the balance position, the vertical downward direction of the $X$ axis as the positive direction, the main motion mode of the sensor as the vertical direction, and the motion differential equation as:

$$
\mathrm{m} \ddot{x}+\mathrm{cx}+\mathrm{kx}=\mathrm{H} \sin \omega \mathrm{t}
$$

Divide both sides of Equation (7) by m:

$$
\ddot{x}+2 n \dot{x}+p_{n}^{2} x=h \sin \omega t
$$

where $\mathrm{p}_{\mathrm{n}}^{2}=\frac{\mathrm{k}}{\mathrm{m}}, 2 \mathrm{n}=\frac{\mathrm{c}}{\mathrm{m}}, \mathrm{h}=\frac{\mathrm{H}}{\mathrm{m}}, \mathrm{c}$ is the viscous damping coefficient, $\mathrm{n}$ is the attenuation coefficient, $h$ is the amplitude of the excitation force on unit mass, $p_{n}$ is the natural circular frequency of the sensor [26]. Its solution consists of two parts:

$$
x(t)=x_{1}(t)+x_{2}(t)
$$


The first part of the solution $\mathrm{x}_{1}(\mathrm{t})$ is the free attenuated vibration of the sensor excited instantaneously. The latter part of the solution $x_{2}(t)$ is a periodic forced oscillation with a circular frequency of $\omega$. The equation of free attenuation motion of the previous part is:

$$
\ddot{x}+2 n \dot{x}+p_{n}^{2} x=0
$$

The solution of Equation (10) at time $t=0$ is:

$$
x_{1}(t)=e^{-n t}\left(x_{0} \cos p_{d} t+\frac{n x_{0}+\dot{x}}{p_{d}} \sin p_{d} t\right)
$$

In Equation (11), there is $p_{d}=\sqrt{p_{n}^{2}-n^{2}}$.

When the time is $t=t_{i}$ :

$$
x_{1}\left(t_{i}\right)=A e^{-n t_{i}} \sin \left(p_{d} t_{i}+\alpha\right)
$$

After one period:

$$
\begin{gathered}
\mathrm{x}_{1}\left(\mathrm{t}_{\mathrm{i}}+\mathrm{T}_{\mathrm{d}}\right)=\sqrt{\mathrm{x}_{0}^{2}+\frac{\left(\dot{\mathrm{x}}_{0}+\mathrm{nx}_{0}\right)^{2}}{\mathrm{p}_{\mathrm{d}}^{2}}} \mathrm{e}^{-\mathrm{n}\left(\mathrm{t}_{\mathrm{i}}+\mathrm{T}_{\mathrm{d}}\right)} \sin \left[\mathrm{p}_{\mathrm{d}}\left(\mathrm{t}_{\mathrm{i}}+\mathrm{T}_{\mathrm{d}}\right)+\alpha\right] \\
\operatorname{tg} \alpha=\frac{\mathrm{x}_{0} \mathrm{p}_{\mathrm{d}}}{\dot{\mathrm{x}}_{0}+\mathrm{nx}_{0}} \\
\mathrm{~T}_{\mathrm{d}}=\frac{2 \pi}{\mathrm{p}_{\mathrm{d}}}
\end{gathered}
$$

The latter part is the forced vibration with a circular frequency of $\omega$. After the free attenuation motion disappears, only the forced vibration exists, and it becomes a steadystate process at this time [27]. Therefore, the motion equation of the sensor system can be written as:

$$
\mathrm{x}_{2}(\mathrm{t})=\frac{\mathrm{h}}{\sqrt{\left(\mathrm{p}_{\mathrm{n}}^{2}-\omega^{2}\right)^{2}+(2 \mathrm{n} \omega)^{2}}} \sin (\omega \mathrm{t}-\varphi)
$$

The displacement $\mathrm{x}$ of the system under the action of excitation force is measured by FBG.

Optical fiber is a material that is sensitive to ultraviolet light. Combined with a special writing technology, the grating is written on the fiber core, so that a periodic refractive index distribution appears inside. Figure 6 is the FBG structure diagram.

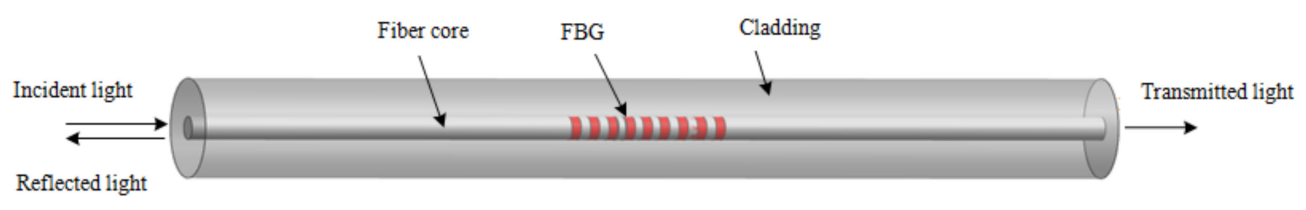

Figure 6. The FBG structure diagram.

When an incident light enters the FBG, part of the light that does not meet the conditions will be reflected back at the grating surface of the grating, and the light waves that meet the conditions will be transmitted forward through the FBG. Subsequently, the spectrum of reflected light and transmitted light will change due to the influence of stress and temperature [28]. The central wavelength $\lambda_{B}$ of the reflected wave of the fiber grating satisfies:

$$
\lambda_{\mathrm{B}}=2 \mathrm{n}_{\mathrm{eff}} \Lambda
$$


In the formula, $\lambda_{B}$ is the central wavelength of the reflected light of the FBG, $\Lambda$ is the period of the grating region of the FBG, and $n_{\text {eff }}$ is the effective refractive index of the fiber core.

Since the early damage of the bearing is weak, no significant temperature changes will occur. Therefore, there is no need to consider the influence of temperature on FBG. When the external conditions only change in stress or strain, the external force causes the FBG to expand and contract in the axial direction. Because of the elasto-optical effect of FBG, the change of the effective refractive index causes the change of the center wavelength of the reflected light [29]:

$$
\frac{\Delta \lambda_{\mathrm{B}}}{\lambda_{\mathrm{B}}}=\left(1-\mathrm{p}_{\mathrm{e}}\right) \Delta \varepsilon
$$

where $\mathrm{p}_{\mathrm{e}}$ is the effective photoelastic constant, and $\varepsilon$ is the strain in the FBG. There is a linear relationship between the central wavelength drift of FBG and axial stress [30].

According to $\varepsilon=\frac{\Delta L}{\mathrm{~L}}$, the change of strain can be converted into the change of FBG center wavelength to reflect the change of external stress.

\section{Structure Design of Resonant Bearing Detection Sensor}

The resonant bearing monitoring sensor mainly includes protective shell, FBG port, mass block, elastomer, bolt, base, etc., as shown in Figure 7.

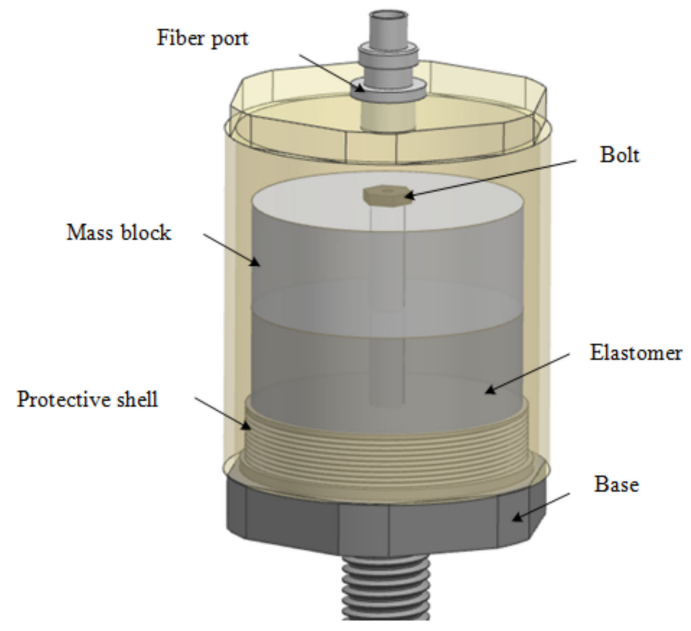

Figure 7. Basic sensor structure.

The protective shell uses 316L stainless steel to form a cavity structure, including an upper port, an outer wall and a screw thread. The upper port is an FBG port, which is used to connect the FBG to an external high-speed demodulator, as shown in Figure 8a. The lower end of the protective shell is connected with the base. The bottom of the base has installation threads. It is used to fix the sensor on the bearing seat under test, as shown in Figure $8 b$.

A mass block with a hole in the center and an elastomer with a hole in the center are arranged in the protective shell, and the mass block is located above the elastomer. A bolt with a hole in the center passes vertically through the center hole of the elastomer and the mass block to cure the FBG [23].

The resonant body structure of the sensor is a structure composed of mass block, elastomer and bolt. The mass block provides gravity loading for its sensor, so the stainless steel with high density and hardness is chosen as the material of the mass block. The elastomer provides a restoring force for the mass block to vibrate back to the equilibrium position, so a polyurethane with relatively high elastic requirements is needed to make the elastomer. The bolt hole encapsulates and solidifies the FBG for shock vibration signal sensing. When the sensor detects the bearing damage vibration, the FBG in the bolt is deformed under the action of the force. When the bearing component is damaged 
and leads to tiny impact, the sensor absorbs the impact energy and generates resonance waves, releasing energy at its own natural frequency. The FBG records the vibration signal waveform and reads out the transient change of the center wavelength through the high-speed FBG demodulator, so as to diagnose whether the bearing is damaged or not.

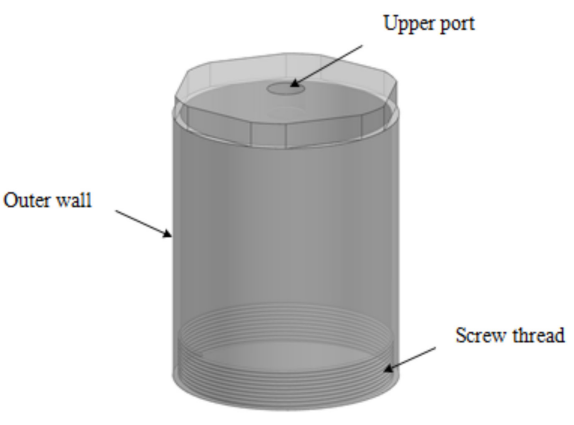

(a)

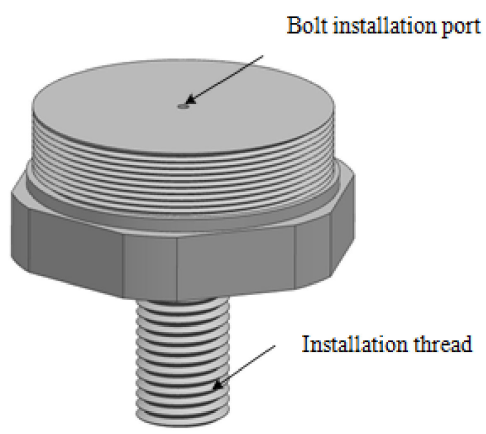

(b)

Figure 8. The structure diagram of the protective shell and the base. (a) The structure diagram of the protective shell; (b) The structure diagram of the base.

The natural frequency calculation formula of the resonance sensor is:

$$
\mathrm{f}=\frac{1}{2 \pi} \sqrt{\frac{\mathrm{K}}{\mathrm{m}}}
$$

The material of the mass block is stainless steel. The mass $\mathrm{m}$ is $26.9 \mathrm{~g}$. The material stiffness $\mathrm{K}$ is $4.75 \times 10^{7} \mathrm{~N} / \mathrm{m}$. The theoretical value of the natural frequency of the sensor is $6691 \mathrm{~Hz}$.

The ANSYS finite element simulation software is used to simulate and analyze the natural frequency of the resonance sensor. Since the sensor structure is relatively complex, in order to simplify the process of extracting the natural frequency of the sensor, the simulation takes the resonant body structure of the sensor for simulation. The simulation analysis steps are divided into seven steps, including simulation modeling, selection of models, selection of materials, meshing, adding constraints, expanding modes, and result analysis [31,32]. The ANSYS finite element simulation interface is shown in Figure 9.

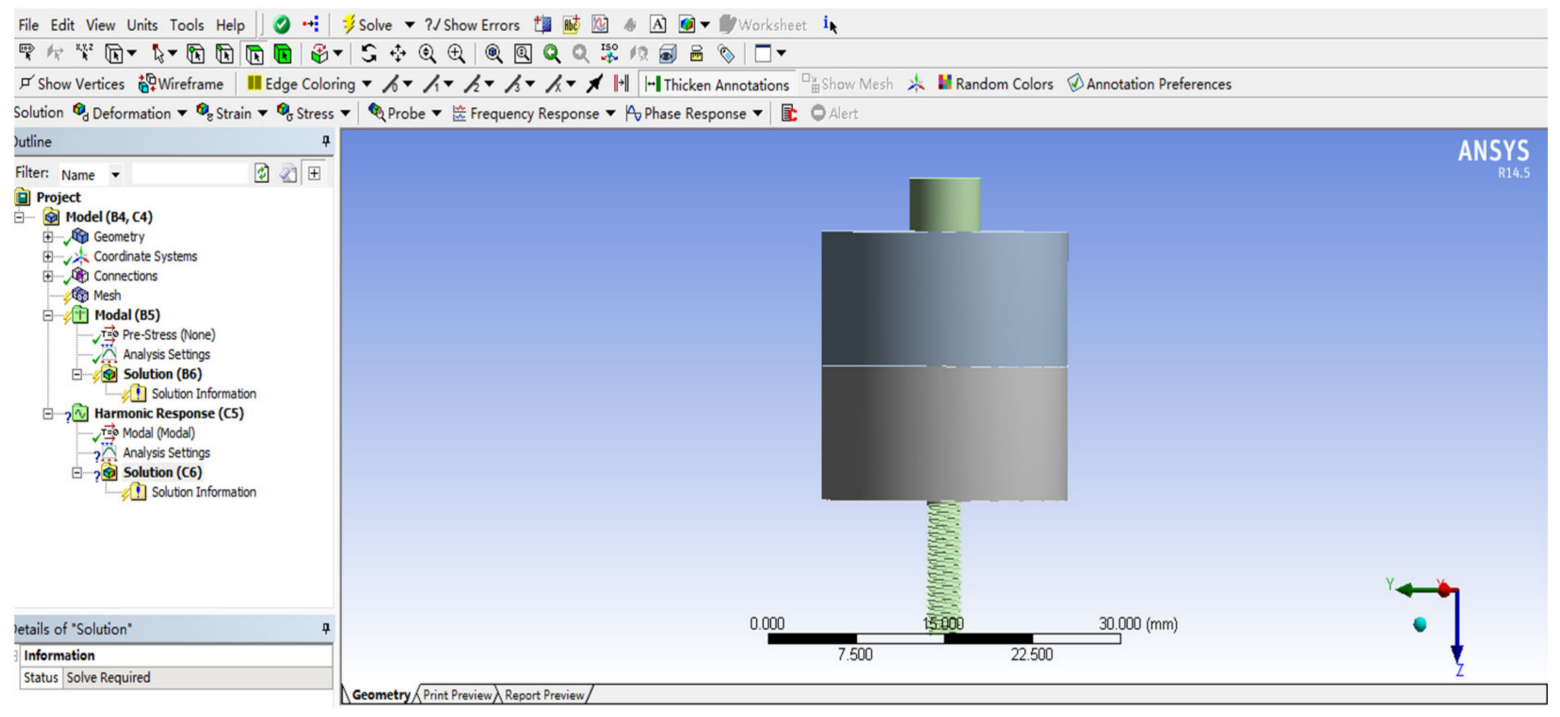

Figure 9. ANSYS finite element simulation diagram. 
The modal analysis result of ANSYS finite element simulation software is the natural frequency of 1-6 order vibration modes. The higher the order obtained, the greater the natural frequency value. The sixth-order natural frequencies are $885 \mathrm{~Hz}, 895 \mathrm{~Hz}, 1367 \mathrm{~Hz}$, $6830 \mathrm{~Hz}, 6857 \mathrm{~Hz}$ and $9770 \mathrm{~Hz}$, as shown in Figure 10.

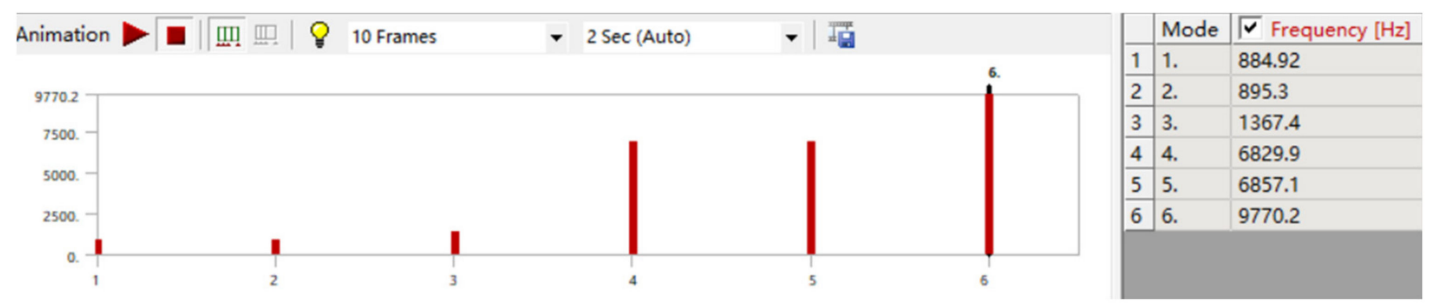

Figure 10. ANSYS finite element simulation of 1-6 natural frequencies.

The experimental measurement method of the natural frequency of the resonant sensor adopts the free vibration method, that is, the ball falls freely to impact the sensor. Using different ball quality and ball height, the effect of different instantaneous impacts on the sensor is obtained. Therefore, the experimental measurement value of the natural frequency of the sensor is $6325 \mathrm{~Hz}$.

The theoretical calculation value of the natural frequency of the resonance sensor, the fourth-order frequency of the ANSYS finite element simulation analysis, and the experimental measurement value are close, verifying the feasibility of the resonance sensor.

\section{Experiment and Analysis}

\subsection{Design of Resonance Sensor Bearing Damage Platform}

The main components of the resonant bearing damage simulation platform include three parts, namely the resonant sensor, the bearing damage platform and the FBG demodulation system. Figure 11 shows the bearing damage simulation platform device. Damaging bearing was installed in bearing pethole 1, normal bearing was installed in bearing pethole 2 , resonance sensor was installed on bearing pethole 1 , and the sensor was fixed in the screw hole directly above the bearing pethole to measure the impact vibration signal of bearing damage. The shaft rod material is bearing steel (high carbon chromium steel), which can act as gravity loads. When the bearing is damaged, the vibration and impact are transmitted outwardly from the contact point in a hemispherical form. If the bearing is damaged, it will cause the loss of energy, so the damage signal of the bearing can be accurately measured.

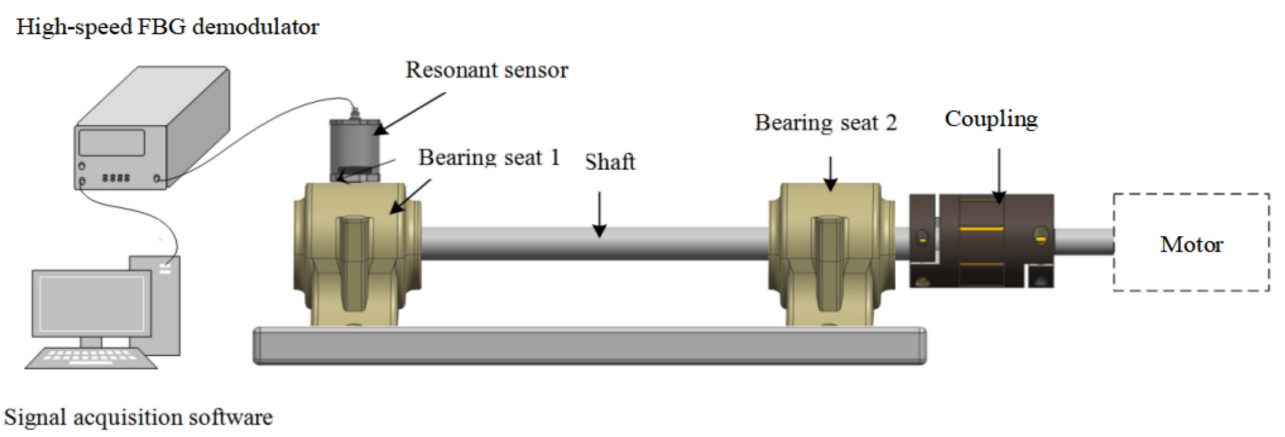

Figure 11. Platform device for bearing damage simulation.

The FBG used in the experiment uses $125 \mu \mathrm{m}$ SMF-28 optical fiber carrying hydrogen. It was made by writing hydrogen-carrying fiber with an excimer laser. The length of the grating region is $10 \mathrm{~mm}$. The center wavelength is $1550 \mathrm{~nm}$. The $3 \mathrm{~dB}$ bandwidth is $0.2 \mathrm{~nm}$. The reflectivity is $95 \%$. The grating region is protected by a gold plating process to improve the durability of the sensor. 
The demodulation of the FBG center wavelength was read by an FBG demodulator based on a high-speed scanning laser. The working wavelength range of the demodulator is $1525-1565 \mathrm{~nm}$. The center wavelength demodulation speed is $200 \mathrm{kHz} / \mathrm{s}$. The wavelength resolution is $1 \mathrm{pm}$. The wavelength switching time interval is $20 \mathrm{~ns} / \mathrm{step}$. Among them, the high-speed scanning laser is the core component of the demodulator, and its spectral line width is $2 \mathrm{MHz}$.

The bearing used in the experimental platform is a deep groove ball bearing. The selected bearing model is the Harbin Bearing 7307. The number of rolling elements is 8 . The contact angle is $0^{\circ}$. The diameter of the inner ring is $35 \mathrm{~mm}$. The diameter of the outer ring is $80 \mathrm{~mm}$. The diameter of the rolling element is $14.5 \mathrm{~mm}$. The driving motor speed is 5 round/s. From Equations (3)-(5), the fault characteristic frequency of the bearing inner ring, outer ring, rolling element and cage can be obtained, as shown in Table 1.

Table 1. Fault characteristic frequency of rolling bearing.

\begin{tabular}{ccccc}
\hline Fault Type & Inner Ring & Outer Ring & Rolling Element & Cage \\
\hline Fault characteristic frequency $/ \mathrm{Hz}$ & 25 & 15 & 18.57 & 1.87 \\
\hline
\end{tabular}

In order to improve the accuracy of the sensor simulation test and simulate the damage of the bearing in actual operation, the line cutting method was used to process the damage defect in the bearing inner ring of the bearing seat 1 . The depth of the contact point between the rolling body and the inner ring defect is $0.5 \mathrm{~mm}$. Figure 12 shows a schematic diagram of the damaged planing surface of the bearing inner ring.

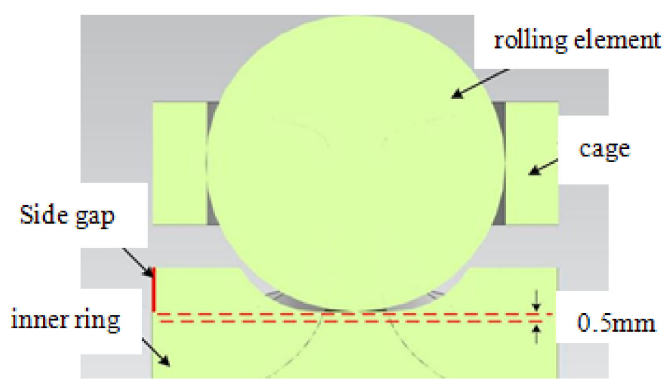

Figure 12. Schematic diagram of the damaged planed surface of the bearing inner ring.

\subsection{Analysis of Bearing Damage Test Data}

Damage bearing and normal bearing, respectively, are driven by a motor to generate continuous impact. Figure 13 shows the time domain characteristic comparison curve of the impact response of the resonance sensor. As the bearing rotates, the position of the damage point in the inner ring changes constantly, and the amplitude of the damage impacted signal changes periodically. In Figure $13 b$, there is an obvious cycle of about 0.04 s shock signal.

The cepstrum analysis of the time domain signal of the damage bearing is shown in Figure 14. Cepstrum is a method for detecting periodic components in a complex spectrum [33-35]. According to Figure 14, there is an obvious cycle of about 0.04 s shock signal at the frequency of $25 \mathrm{~Hz}$. The theoretical calculation for bearing inner ring fault characteristic frequency is $25 \mathrm{~Hz}$. This coincides with the frequency of the generalized resonance wave, also with a frequency of $25 \mathrm{~Hz}$. According to the frequency of the generalized resonance wave and the characteristic frequency of the bearing inner ring fault, it is determined that the bearing damage occurs in the inner ring component, which is consistent with the bearing processing damage component. 


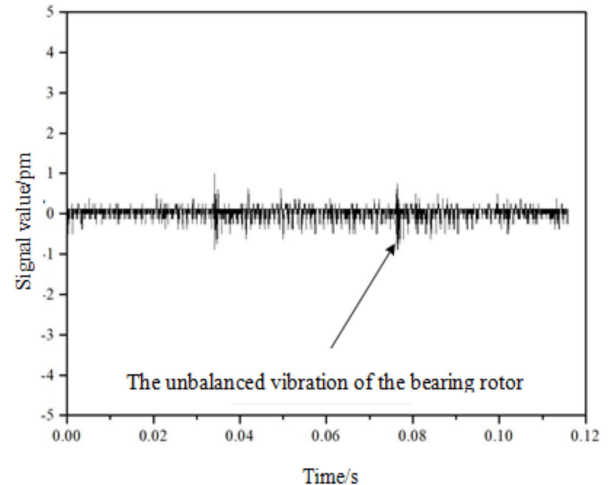

(a)

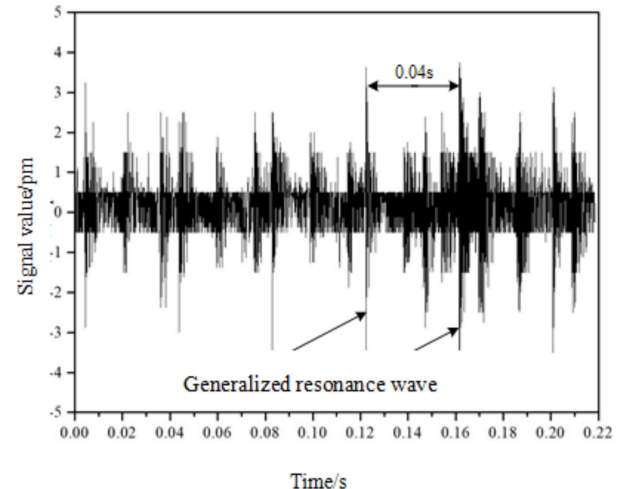

(b)

Figure 13. Time domain characteristic curve of shock response of sensor. (a) Time domain characteristic curve of normal bearing; (b) Time domain characteristic curve of damage bearing.

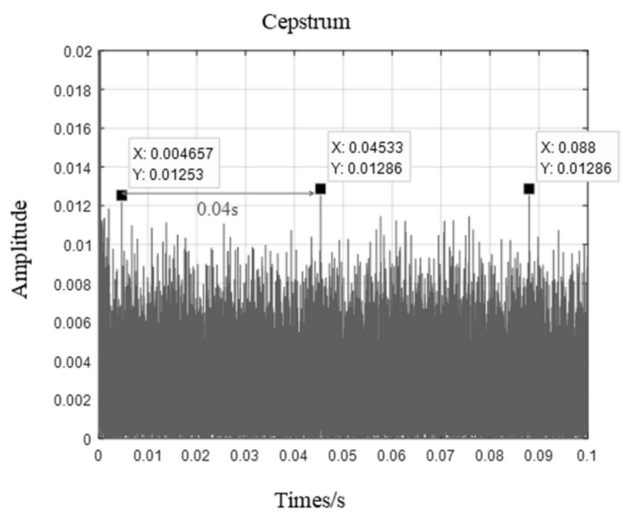

Figure 14. Cepstrum analysis on the time domain characteristic curve of the damaged bearing.

Comparison curves of amplitude-frequency characteristics of impact response are shown in Figure 15. Figure 15a is the amplitude-frequency characteristic curve of the normal bearing with uniform speed rotation, and Figure $15 \mathrm{~b}$ is the amplitude-frequency characteristic curve of the damage bearing with uniform speed rotation. When the bearing is continuously impacted by the sensor, a peak value of $5970 \mathrm{~Hz}$ appears in the amplitudefrequency characteristic curve of the sensor vibration, which is basically consistent with the value of the natural frequency of the sensor, $6325 \mathrm{~Hz}$. It proves that the sensor generates generalized resonance after absorbing the bearing impact, and the frequency is the natural frequency of the sensor. It is also observed in Figure $15 \mathrm{~b}$ that a small peak with an amplitude of 0.09686 appeared at the frequency of $945.8 \mathrm{~Hz}$, which is the vibration frequency generated by the unbalanced vibration of the bearing rotor.

The power spectrum curve of impact response is shown in Figure 16. Figure 16a is the power spectrum curve when the normal bearing rotates at a uniform speed, and Figure $16 \mathrm{~b}$ is the power spectrum curve when the damage bearing rotates at a uniform speed. According to Figure 16, when the bearing is running at a uniform speed, the energy caused by unbalanced vibration of the rotor when the bearing is damaged is $35.72 \mathrm{~dB}$, which is higher than the energy caused by unbalanced vibration of the rotor when the bearing is normal. At the same time, when the bearing is damaged, generalized resonance is generated. Energy is generated at the natural frequency caused by the generalized resonance wave, and the energy value is $115.5 \mathrm{~dB}$, which is much higher than the energy caused by the unbalanced vibration of the rotor. 


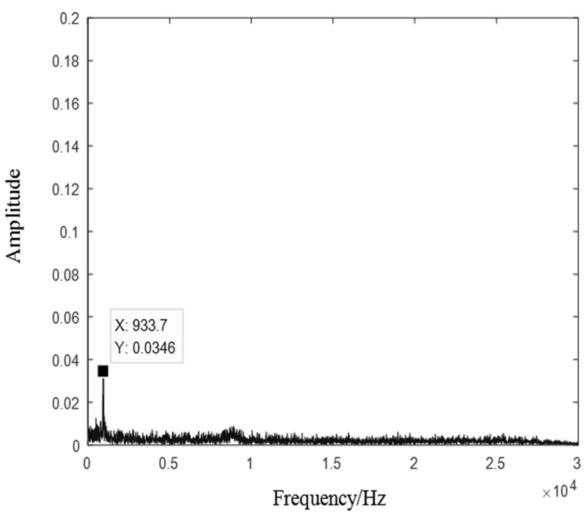

(a)

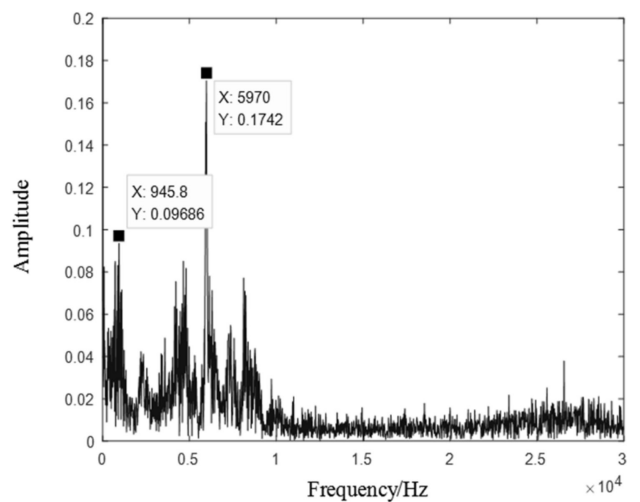

(b)

Figure 15. Amplitude-frequency characteristic curve of sensor impact response. (a) Amplitude-frequency characteristic curve of normal bearing at uniform speed; (b) Amplitude-frequency characteristic curve of damage bearing at uniform speed.

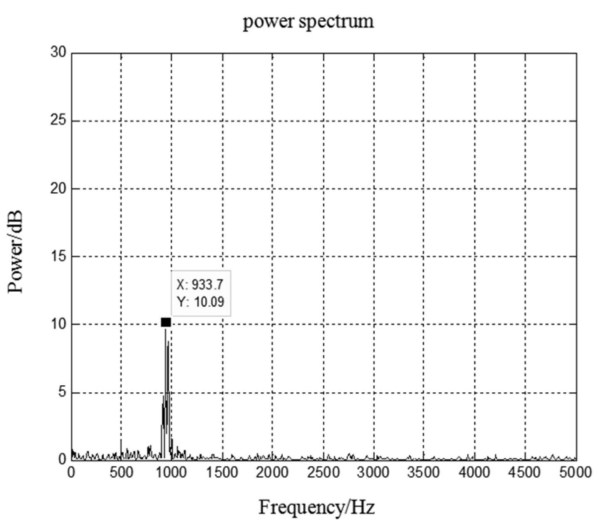

(a)

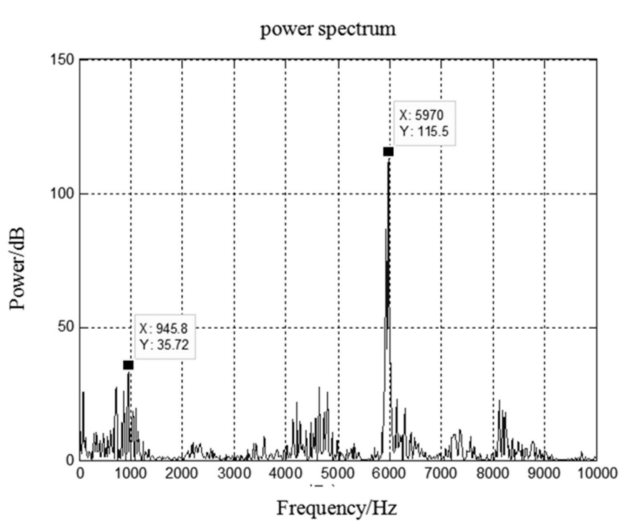

(b)

Figure 16. Power spectrum curve of sensor shock response. (a) Power spectrum curve when the normal bearing rotates at uniform speed; (b) Power spectrum curve when the damage bearing rotates at uniform speed.

\section{Discussion}

Based on the comprehensive analysis of the time domain, frequency domain and power spectrum characteristic curves of damage and normal bearing, the following conclusions can be drawn.

(1) When the following two conditions are met, it can be determined that the bearing is damaged. Case 1: A periodic continuous generalized resonance wave appeared in the time domain signal characteristic curve. Case 2: The natural frequency of the sensor appeared in the frequency domain characteristic curve. When the above two conditions exist, it means that the bearing is damaged, and the micro-shock signal generated by the damage and the sensor have a generalized resonance phenomenon.

(2) The cycle and frequency of the damage impact signal can be obtained from the cepstrum characteristic curve and the time domain signal characteristic curve. This value is close to the theoretically calculated value of the bearing inner ring fault characteristics. It can be determined that the bearing damage is located in the bearing inner ring, which is the same as the bearing processing damage in the experiment. This can realize the diagnosis of bearing damage position.

(3) The resonance frequency caused by bearing damage is close to $6000 \mathrm{~Hz}$, reaching the high-frequency range, effectively avoiding the interference of low-frequency signals. 
(4) The vibration signal obtained by the FBG demodulator has a pure spectrum characteristic curve and no electromagnetic interference.

\section{Conclusions}

To sum up, this paper proposes an early fault diagnosis method for bearings based on FBG sensor monitoring. The radial bearing with symmetric load distribution is used as the research object. Combined with the principle of generalized resonance, the FBG is used as a sensitive element to realize early bearing damage monitoring. The damaged part of the bearing judged by this method is consistent with the damaged part of the bearing after processing, which verifies the feasibility of the fiber Bragg grating sensor to monitor the weak fault of the symmetrical bearing.

Author Contributions: Conceptualization, S.S. and G.L.; software, H.Z. and Y.J.; formal analysis, X.C. and H.L.; writing—original draft preparation, B.Z.; writing—review and editing, X.C. All authors have read and agreed to the published version of the manuscript.

Funding: This research is funded by Heilongjiang Provincial Science and Technology Department, grant number GZ11A306, Heilongjiang University, grant number HDJMRH201904.

Data Availability Statement: Not applicable.

Conflicts of Interest: The authors declare no conflict of interest.

\section{References}

1. Shi, D.Z.; Min, G. Analysis and treatment of high bearing temperature occurred on a 300 MW turbine generator unit. Power Syst. Eng. 2019, 5, 110-115.

2. Xue, T.W.; Chun, Y.M.; Jing, F.Y.; Jing, S.X.; Yian, Y.C.; Leng, J.F. Research and application on vibration fault diagnosis of mine ventilator bearing. Coal Mine Mach. 2013, 4, 45-49.

3. Jun, Q.L.; Zhen, P.W.; Depot, D.L. Application research of thermal balance in bearing temperature analysis for locomotive traction motor. Railw. Locomot. Car 2019, 11, 57-64.

4. Wei, S.; Yu, X.C.; Jia, D.Z.; Guo, Z.L. Research on measurement results consistency method of rolling bearing vibration measuring instrument. Mech. Eng. 2019, 5, 130-135.

5. Yüksel, K.; Kinet, D.; Moeyaert, V.; Kouroussis, G.; Caucheteur, C. Railway monitoring system using optical fiber grating accelerometers. Smart Mater. Struct. 2018, 27, 105033. [CrossRef]

6. Li, N.; Wei, P.; Mo, H.; Mei, S.K.; Li, M. Bearing state monitoring using a novel fiber Bragg grating acoustic emission technique. J. Vib. Shock 2015, 34, 172-177.

7. Gupta, P.; Pradhan, M. Fault detection analysis in rolling element bearing: A review. Mater. Today Proc. 2017, 4, 2085-2094. [CrossRef]

8. Roveri, N.; Carcaterra, A.; Sestieri, A. Real-time monitoring of railway infrastructures using fibre Bragg grating sensors. Mech Syst. Signal Process. 2015, 60-61, 14-28. [CrossRef]

9. You, P.; Lin, L.; Wang, H. Cooperative mechanism of generalized stochastic resonance in a time-delayed fractional oscillator with random fluctuations on both mass and damping. Chaos Solitons Fractals 2020, 135, 109789. [CrossRef]

10. Huang, X.; Lin, L.; Wang, H. Generalized Stochastic Resonance for a Fractional Noisy Oscillator with Random Mass and Random Damping. J. Stat. Phys. 2020, 178, 1201-1216. [CrossRef]

11. Jayakanth, J.; Chandrasekaran, M.; Pugazhenthi, R. Impulse excitation analysis of material defects in ball bearing. Mater. Today Proc. 2021, 39, 717-724. [CrossRef]

12. Liu, J.; Xu, Y.; Pan, G. A combined acoustic and dynamic model of a defective ball bearing. J. Sound Vib. 2021, 501, 116029. [CrossRef]

13. Zhang, H.; Borghesani, P.; Smith, W.A.; Randall, R.B.; Shahriar, R.; Peng, Z. Tracking the natural evolution of bearing spall size using cyclic natural frequency perturbations in vibration signals. Mech. Syst. Signal Process. 2021, 151, 107376. [CrossRef]

14. Luo, M.; Guo, Y.; Wu, X.; Na, J. An analytical model for estimating spalled zone size of rollingelement bearing based on dual-impulse time separation. J. Sound Vib. 2019, 453, 87-102. [CrossRef]

15. Zhang, Y.; Fang, B.; Kong, L.; Li, Y. Effect of the ring misalignment on the service characteristics of ball bearing and rotor system. Mech. Mach. Theory 2020, 151, 103889. [CrossRef]

16. Ahmadi, A.M.; Petersen, D.; Howard, C. A nonlinear dynamic vibration model of defective bearings-The importance of modelling the finite size of rolling elements. Mech. Syst. Signal Process. 2015, 52-53, 309-326. [CrossRef]

17. Vale, C.; Bonifácio, C.; Seabra, J.; Calçada, R.; Mazzino, N.; Elisa, M.; Terribile, S.; Anguita, D.; Fumeo, E.; Saborido, C.; et al. Novel Efficient Technologies in Europe for Axle Bearing Condition Monitoring. Transp. Res. Procedia 2016, 14, 635-644. [CrossRef] 
18. Bechhoefer, E.; Schlanbusch, R. Generalized Prognostics Algorithm Using Kalman Smoother. IFAC PapersOnLine 2015, 48, 97-104. [CrossRef]

19. Li, C.; Sánchez, R.V.; Zurita, G.; Lozada, M.C.; Cabrera, D. Rolling element bearing defect detection using the generalized synchrosqueezing transform guided by time-frequency ridge enhancement. ISA Trans. 2016, 60, 274-284. [CrossRef]

20. Wang, G.; Zhao, B.; Xiang, L.; Li, W.; Zhu, C. Information interval spectrum: A novel methodology for rolling-element bearing diagnosis. Measurment 2021, 183, 109899. [CrossRef]

21. Liu, Y.; Xiong, Z. A generalized stochastic resonance based instantaneous frequency estimation method under low SNR. Mech. Syst. Signal Process. 2021, 164, 108269. [CrossRef]

22. Xiao, L.; Zhang, X.; Lu, S.; Xia, T.; Xi, L. A novel weak-fault detection technique for rolling element bearing based on vibrational resonance. J. Sound Vib. 2019, 438, 490-505. [CrossRef]

23. Lyu, G.; Jiang, Y.; Wang, C.; Zhao, J.; Che, G.; Jiang, X. Simulation design of fiber Bragg grating resonant sensor for train bearing damage detection. In Proceedings of the 2018 Asia Communications and Photonics Conference (ACP), Hangzhou, China, 26-29 October 2018.

24. Yang, J.; Fan, S.; Li, B.; Huang, R.; Shi, Y.; Shi, B. Dynamic modeling of liquid impulse pressure generator for calibration of pressure sensors. Sens. Actuators A Phys. 2018, 279, 120-131. [CrossRef]

25. Choi, S.; Cho, S.-H.; Park, C.-W.; Shin, J.-H. A novel cardiac spectral envelope extraction algorithm using a single-degree-offreedom vibration mode. Biomed. Signal Process. Control 2015, 18, 169-173. [CrossRef]

26. Malas, A.; Chatterjee, S. Amplitude Controlled Adaptive Feedback Resonance in a Single Degree-of-Freedom Mass-Spring Mechanical System. Procedia Eng. 2016, 144, 697-704. [CrossRef]

27. Chatterjee, S.; Malas, A. On the stiffness-switching methods for generating self-excited oscillations in simple mechanical systems. J. Sound Vib. 2012, 331, 1742-1758. [CrossRef]

28. Peng, J.; Zhou, X.; Jia, S.; Jin, Y.; Xu, S.; Chen, J. High precision strain monitoring for lithium ion batteries based on fiber Bragg grating sensors. J. Power Source 2019, 433, 226692. [CrossRef]

29. Zhang, Y.; Qiao, X.; Liu, Q.; Yu, D.; Gao, H.; Shao, M.; Wang, X. Study on a fiber Bragg grating accelerometer based on compliant cylinder. Opt. Fiber Technol. 2015, 26, 229-233. [CrossRef]

30. Chan, T.; Yu, L.; Tam, H.Y.; Ni, Y.-Q.; Liu, S.; Chung, W.; Cheng, L. Fiber Bragg grating sensors for structural health monitoring of Tsing Ma bridge: Background and experimental observation. Eng. Struct. 2006, 28, 648-659. [CrossRef]

31. Kumar, P.S.; Naveenkumar, R.; Moorthy, S.L.; Meignanamoorthy, M.; Ravichandran, M. Heat transfer analysis for different materials of ball bearing using ANSYS. Mater. Today Proc. 2020, 12. [CrossRef]

32. Tang, Z.; Sun, J. The Contact Analysis for Deep Groove Ball Bearing Based on ANSYS. Procedia Eng. 2011, 23, 423-428.

33. Jiang, F.; Ding, K.; He, G.; Du, C. Sparse dictionary design based on edited cepstrum and its application in rolling bearing fault diagnosis. J. Sound Vib. 2021, 490, 115704. [CrossRef]

34. Randall, R. A history of cepstrum analysis and its application to mechanical problems. Mech. Syst. Signal Process. 2017, 97, 3-19. [CrossRef]

35. Braun, S. Cepstrum based methods. Mech. Syst. Signal Process. 2019, 128, 674-676. [CrossRef] 